\title{
Effect of Tween 80 Surfactant on the Electropolymerization and Corrosion Performance of Polyaniline on Mild Steel
}

\author{
B. A. Abd-El-Nabey, ${ }^{1, *}$, O. A. Abdullatef ${ }^{3}$, G. A. El-Naggar ${ }^{2}$, E. A. Matter ${ }^{2}$ and R. M. Salman ${ }^{2}$ \\ ${ }^{1}$ Faculty of Science, Chemistry Department, Alexandria University, P.O.Box 426, Alexandria 21321, \\ Egypt \\ ${ }^{2}$ Faculty of Science, Damanhur University, Damanhur, Egypt \\ ${ }^{3}$ Pharos University, Faculty of Pharmacy, Alexandria, Egypt \\ *E-mail: beshirabdelnaby2015@gmail.com
}

doi: $10.20964 / 110402721$

Received: 1 January 2016 / Accepted: 8 February 2016 / Published: 1 March 2016

Polyaniline conducting polymer have been electropolymerized from aniline monomer on mild steel surface by cyclic voltametry method in aqueous oxalic acid solution and different concentrations of Tween 80 as surfactant. Characterization of coatings was carried out by scanning electron microscope SEM. Corrosion behavior of the polymer coated mild steel electrodes was investigated in $0.5 \mathrm{M} \mathrm{H}_{2} \mathrm{SO}_{4}$ solution by potentiodynamic polarization and electrochemical impedance spectroscopy EIS. Adsorption of the polymer on the metal surface was examined by applying the Langumir adsorption isotherm to fit the experimental data. The mechanism of action of the surfactant in the electropolymerization process has been investigated and discussed.

Keywords: Electropolymerization, surfactant, polyaniline, corrosion, impedance.

\section{$\underline{\text { FULL TEXT }}$}

(C) 2016 The Authors. Published by ESG (www.electrochemsci.org). This article is an open access article distributed under the terms and conditions of the Creative Commons Attribution license (http://creativecommons.org/licenses/by/4.0/). 